\title{
On the Mechanisms for Martensite Formation in YAG Laser Welded Austenitic NiTi
}

\author{
J. P. Oliveira ${ }^{1}$ - F. M. Braz Fernandes ${ }^{1} \cdot$ R. M. Miranda ${ }^{2} \cdot$ N. Schell ${ }^{3}$
}

Published online: 4 March 2016

(C) ASM International 2016

\begin{abstract}
Extensive work has been reported on the microstructure of laser-welded NiTi alloys either superelastic or with shape memory effect, motivated by the fact that the microstructure affects the functional properties. However, some effects of laser beam/material interaction with these alloys have not yet been discussed. This paper aims to discuss the mechanisms for the occurrence of martensite in the heat-affected zone and in the fusion zone at room temperature, while the base material is fully austenitic. For this purpose, synchrotron radiation was used together with a simple thermal analytic mathematical model. Two distinct mechanisms are proposed for the presence of martensite in different zones of a weld, which affects the mechanical and functional behavior of a welded component.
\end{abstract}

Keywords $\mathrm{NiTi} \cdot$ Laser welding - Synchrotron radiation . Martensite $\cdot \mathrm{X}$-ray diffraction - Precipitation phenomena . $\mathrm{Ni}_{4} \mathrm{Ti}_{3}$

J. P. Oliveira

jp.oliveira@campus.fct.unl.pt

1 CENIMAT/I3N, Departamento de Ciências dos Materiais, Faculdade de Ciências e Tecnologia, FCT, Universidade Nova de Lisboa, 2829-516 Caparica, Portugal

2 UNIDEMI, Departamento de Engenharia Mecânica e Industrial, Faculdade de Ciências e Tecnologia, FCT, Universidade Nova de Lisboa, 2829-516 Caparica, Portugal

3 Helmholtz-Zentrum Geesthacht, Institute of Materials Research, 21502 Geesthacht, Germany

\section{Introduction}

Ni-Ti shape memory alloys (SMAs) are known to exhibit superelasticity, shape memory effect, and biocompatibility, which make them a good candidate for several types of applications [1]. Due to the low formability of these alloys, a suitable joining technique must be used to obtain devices and components with complex geometries [2].

Laser welding of these SMAs is being studied in the last years in order to fully understand the effects of this joining technique on the microstructure and functional properties of these materials.

Literature can be found about the microstructure [3-5] and the effects of laser welding on the functional properties of the joints [2, 6-8]. However, some consequences of the interaction between the laser beam and these materials were not yet fully discussed despite the effects observed and reported. One of those effects is the existence of a different phase from the base material at room temperature in the heat-affected zone (HAZ) and in the fusion zone (FZ) after the welding.

It is a well-known fact that, in Ni-Ti SMAs, the transformation temperatures are composition dependent. A minor change in its composition significantly modifies the transformation temperatures of these materials [1]. In particular, for a Ni-rich alloy, a depletion in Ni causes a significant raise on the transformation temperatures, while for Ti-rich alloys, an enrichment in Ni does not significantly change these temperatures.

In this work it was observed that the base material was fully austenitic at room temperature and the heat-affected zone and fusion zone had both martensite and austenite after welding. Understanding the cause for this microstructural change is of great importance as it brings significant changes in the mechanical behavior of the welded NiTi joints. 
A change in the transformation temperatures in the laser welding region has been reported in other works [2, 7, 9, 10]. More recently, Khan et al. [11] have studied the laser processing of a NiTi shape memory alloy that was austenitic at room temperature, in order to obtain, in a controlled manner, an increase of the transformation temperatures that they related to the differential volatilization of $\mathrm{Ni}$ and $\mathrm{Ti}$ from the liquid pool. This way, the authors were able, depending on the process parameters, to obtain martensite at room temperature in the laser-processed region. The same reasoning may be applied to laser welding. But, in our study, we have identified two different mechanisms operating in different regions of the weld: differential volatilization of $\mathrm{Ni}$ and $\mathrm{Ti}$ in the fusion zone and $\mathrm{Ni}_{4} \mathrm{Ti}_{3}$ precipitation in the heat-affected zone.

The small dimensions of the HAZ and FZ, characteristic of laser welding, make it difficult to ensure that only one or the other region is being analyzed by DSC, even when using precision cutting for the sample preparation, as it is recognized by other authors [7, 9, 12].

So, in the present work, synchrotron radiation was used for a detailed microstructural analysis along the weld, in parallel with a simple thermal model based on the work of Rosenthal [13] that was used to estimate the thermal cycle during laser welding.

\section{Experimental Procedure}

Near-equiatomic (50.8 at \% $\mathrm{Ni}$ ) $\mathrm{Ni}-\mathrm{Ti}$ plates, $1.0 \mathrm{~mm}$ thick, supplied in the condition of flat annealed, were buttwelded with a Nd:YAG laser source from Rofin-Sinar, operating in continuous wave mode. The samples to be welded were positioned, so that the weld was performed perpendicular to the base material rolling direction. Helium and Argon were used to create an inert atmosphere in the weld area, both on the top and on the weld root. Table 1 summarizes the welding parameters used. The welding parameters were chosen in order to produce sound welds, thus the heat input necessary has a small admissible range. Though it is known that an increase in the heat input originates lower cooling rates, this effect is negligible for the range of heat inputs tested.

Differential Scanning Calorimetry (DSC) was used to characterize the structural transformation temperatures of the base material. Liquid nitrogen was used to cool down the system to $-160{ }^{\circ} \mathrm{C}$. Upon heating, the maximum temperature was of about $70{ }^{\circ} \mathrm{C}$. The cooling and heating rates were set at $10{ }^{\circ} \mathrm{C} / \mathrm{min}$.

X-Ray Diffraction was performed at HEMS-High Energy Materials Science beamline (PETRA III, DESY, Hamburg, Germany). It used a wavelength of $0.1426 \AA$ (87 keV). A 2D detector was used and the tests were held at room temperature $\left(21^{\circ} \mathrm{C}\right)$. Several scans were recorded starting in the base material, passing through the heat-affected zone and the fusion zone and finishing again in the base material. A length of approximately $6.0 \mathrm{~mm}$ was analyzed, with the weld center line positioned at half distance, in steps of $0.1 \mathrm{~mm}$. The beam spot was of $0.2 \times 0.2 \mathrm{~mm}$ and the exposure time was kept between 5 and $10 \mathrm{~s}$. A post-weld heat treatment was performed on sample A for $60 \mathrm{~min}$ at $450{ }^{\circ} \mathrm{C}$ in order to induce precipitation phenomena. The structural characterization by synchrotron X-ray diffraction of this sample was also performed.

\section{Results and Discussion}

Phase transformation temperatures measured by DSC in the base material revealed, upon cooling, the existence of two exothermic peaks indicating a two-step transformation from austenite to R-phase and, later, to martensite. Upon heating, only one endothermic peak is observed corresponding to the transformation of martensite into austenite (Fig. 1).

Three X-ray diffractograms corresponding to the base material, heat-affected zone, and fusion zone of sample B, at room temperature, are depicted in Fig. 2. For an interplanar distance, d, ranging from 1.90 to $2.45 \AA$, where the most relevant peaks of the NiTi system can be found, there is a clear distinction between the base material, the heataffected zone, and the fusion zone. The base material is fully austenitic, but in the heat-affected zone and the fusion zone extra martensite peaks are detected, while the austenite peak still remains.

Explaining the mechanisms that lead to the presence of the observed microstructure, namely the martensitic phase, in the heat-affected zone and in the fusion zone, while the base material is fully austenitic, is the focus of this work.

As the mechanisms that explain the existence of martensite in the heat-affected zone and in the fusion zone
Table 1 Welding parameters of the analyzed samples

\begin{tabular}{lllll}
\hline Sample reference & $\begin{array}{l}\text { Power } \\
(\mathrm{W})\end{array}$ & $\begin{array}{l}\text { Welding speed } \\
(\mathrm{mm} / \mathrm{s})\end{array}$ & $\begin{array}{l}\text { Heat input } \\
(\mathrm{J} / \mathrm{cm})\end{array}$ & $\begin{array}{l}\text { Focused beam diameter } \\
(\mathrm{mm})\end{array}$ \\
\hline A & 990 & 20 & 495 & 0.45 \\
B & 1485 & 25 & 594 & \\
\hline
\end{tabular}




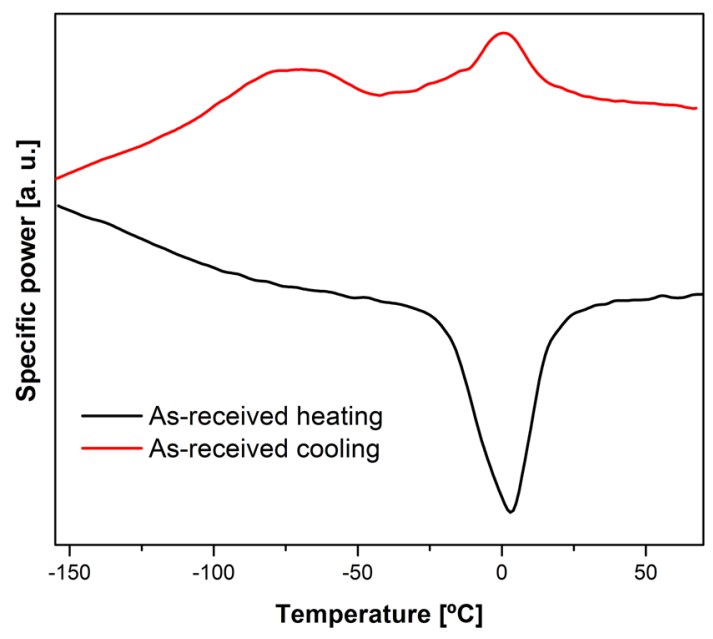

Fig. 1 Differential scanning calorimetry measurements of the base material

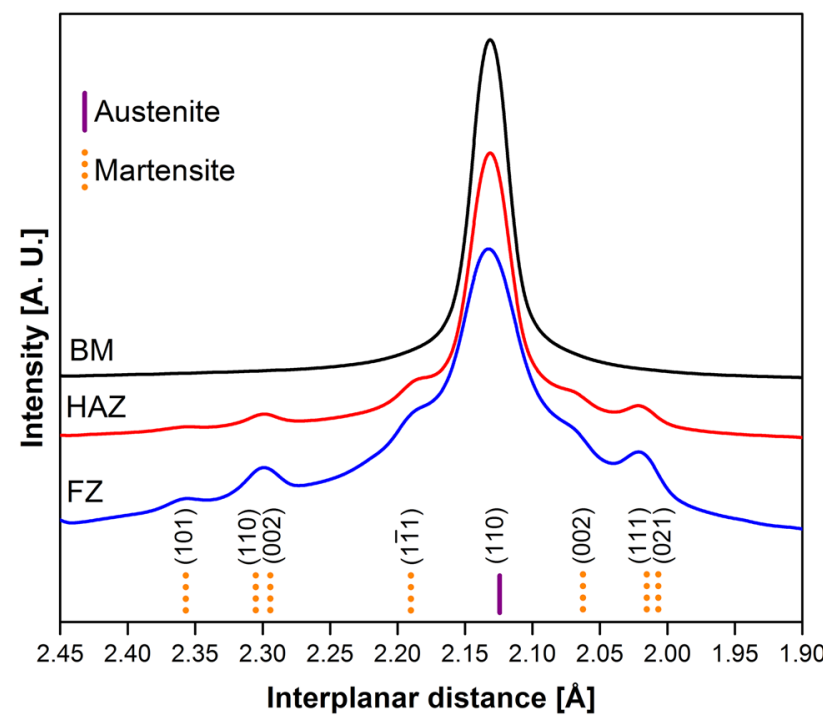

Fig. 2 Diffractograms of base material (BM), heat-affected zone (HAZ), and fusion zone (FZ) of sample B

are different, the subsequent analysis is divided in order to analyze each region separately.

\section{Existence of Martensite in the Heat-Affected Zone}

Since martensite was observed in both samples (as observed in Fig. 2 for sample B), results and discussion will be presented for sample A. In fact, the variation of structural modifications due to the weld thermal cycle is similar in both samples, as well as the formation mechanisms of martensite in the heat-affected zone.

Overlaying, in a continuous way, the diffractograms of sample A (Fig. 3), aside from the presence of martensite peaks in the heat-affected zone and fusion zone with a minor decrease in the austenite peak intensity, a broad peak can be noticed on the right-hand side of the (110) austenite peak in the strip of powder patterns corresponding to the heat-affected zone. This feature is marked with an arrow in Fig. 3. Martensite peaks are expected to occur in the neighborhood of the (110) austenite peak, meaning that the existence of martensite in the heat-affected zone can originate this singularity. Aside from martensite, for interplanar spacings near the (110) austenite peak, precipitates, such as $\mathrm{Ni}_{4} \mathrm{Ti}_{3}$, are also expected to occur.

Sample A was heated up to $150{ }^{\circ} \mathrm{C}$ and in situ x-ray diffraction was performed in a similar way as shown in Fig. 3. The reason for this approach is that $150{ }^{\circ} \mathrm{C}$ is well above the $\mathrm{A}_{\mathrm{f}}$ temperature of the base material, so any remaining martensite, in the heat-affected zone and in the fusion zone, will transform to austenite. However, that temperature is not enough to dissolve any precipitates that can be formed in the Ni-Ti system, meaning that if the broad peak is not present at $150{ }^{\circ} \mathrm{C}$, than it can be assigned to martensite. Otherwise it must be assigned to a given precipitate.

Figure 4 depicts a superposition of the diffractograms of the sample A heated at $150{ }^{\circ} \mathrm{C}$. The martensite peaks have completely disappeared, while the broad peak on the righthand side of the austenite peak is still present (marked with an arrow). The only possibility to explain the observed feature is by the occurrence of precipitation phenomena in the heat-affected zone.

For Ni-rich NiTi shape memory alloys, precipitation of $\mathrm{Ni}_{4} \mathrm{Ti}_{3}, \mathrm{Ni}_{3} \mathrm{Ti}_{2}$, and $\mathrm{Ni}_{3} \mathrm{Ti}$ may occur. $\mathrm{Ni}_{4} \mathrm{Ti}_{3}$ and $\mathrm{Ni}_{3} \mathrm{Ti}_{2}$ are metastable precipitates $[14,15]$ while $\mathrm{Ni}_{3} \mathrm{Ti}$ is the equilibrium precipitate [1]. It is also known that $\mathrm{Ni}_{4} \mathrm{Ti}_{3}$ precipitation is the first to occur and happens for lower temperatures and shorter permanence times, when compared to $\mathrm{Ni}_{3} \mathrm{Ti}_{2}$ and $\mathrm{Ni}_{3} \mathrm{Ti}$.

A detailed TTT diagram for NiTi SMAs was presented by Nishida et al. [16]. Recently, Pelton et al. [17] published another TTT diagram for NiTi SMAs but with short times for the onset of the precipitation phenomena. Pelton et al. tested a NiTi SMA with the same composition as the base material of the samples used in this study. From both TTT diagrams it is possible to infer that $\mathrm{Ni}_{4} \mathrm{Ti}_{3}$ precipitation may occur in small time scale (a few seconds). In Pelton's diagram it is depicted more clearly that $\mathrm{Ni}_{4} \mathrm{Ti}_{3}$ precipitation may occur while crossing the temperature range of 350 to $500{ }^{\circ} \mathrm{C}$ in a short elapsed time, of a couple of seconds.

\section{Modeling of Temperatures and Permanence Times for Precipitation in the Heat-Affected Zone}

To simulate the temperature gradient in the material due to the welding operation, the simple $2 \mathrm{D}$ solution from the Rosenthal equation (Eq. 1) was employed. It can be used in 
Fig. 3 Superposition of the diffractograms of sample A, at room temperature
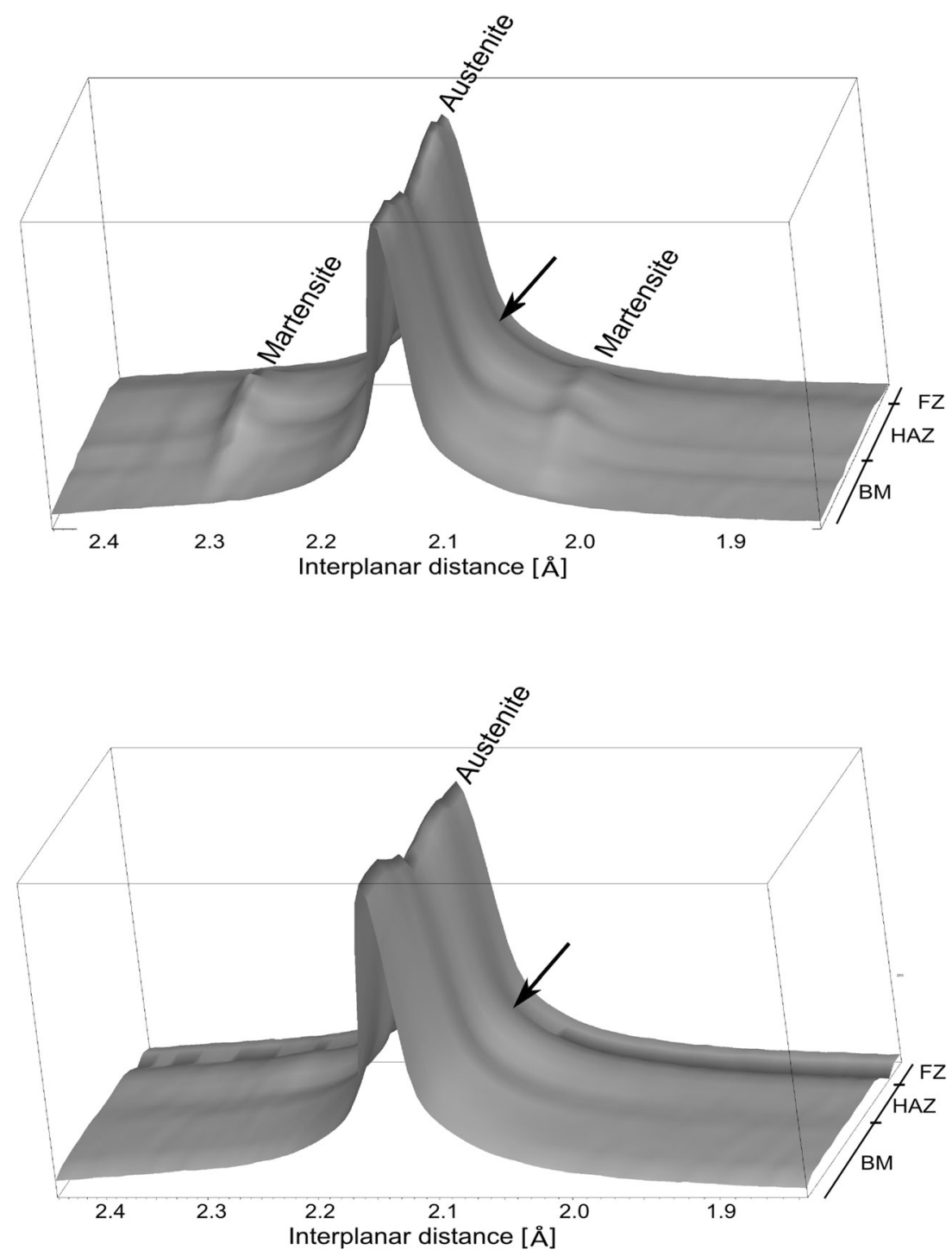

Fig. 4 Superposition of the diffractograms of sample $\mathrm{A}$, at $150{ }^{\circ} \mathrm{C}$
The temperatures reached for sample A, in the heataffected zone, computed from Eq. 1 with the welding parameters tested, and the physical properties of NiTi, are depicted in Fig. 6. According to this equation, the time, in seconds, that the material takes to cross the temperature range from 350 to $500{ }^{\circ} \mathrm{C}$ is within the time interval of Pelton et al. experiments (see Fig. 7). Due to the laser welding characteristics, the holding time at temperatures where precipitation can occur is within the magnitude of a few seconds.

As a consequence of $\mathrm{Ni}_{4} \mathrm{Ti}_{3}$ being a minority phase, its intensity in the diffractograms is expected to be very low. Aside from that aspect, the most intense peak for this precipitate, according to 39-1113 JCPDF card, occurs for an interplanar spacing of $2.092 \AA$, very close to the austenite peak and therefore can be partially overlapped by its tail. All other peaks have a maximum intensity ranging 


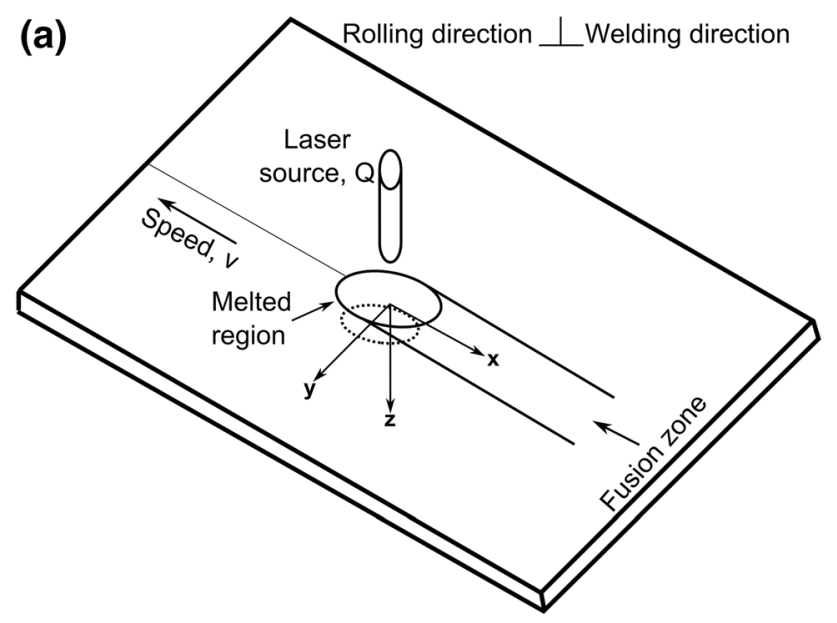

(b)

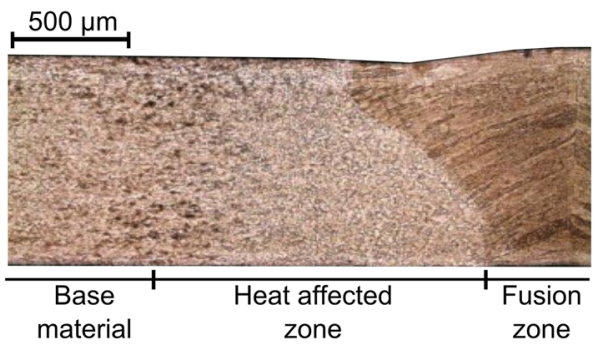

Fig. 5 a Reference system used to determine the temperature gradient in the joint (Adapted from [13]). b Macrograph of a NiTi laser-welded joint

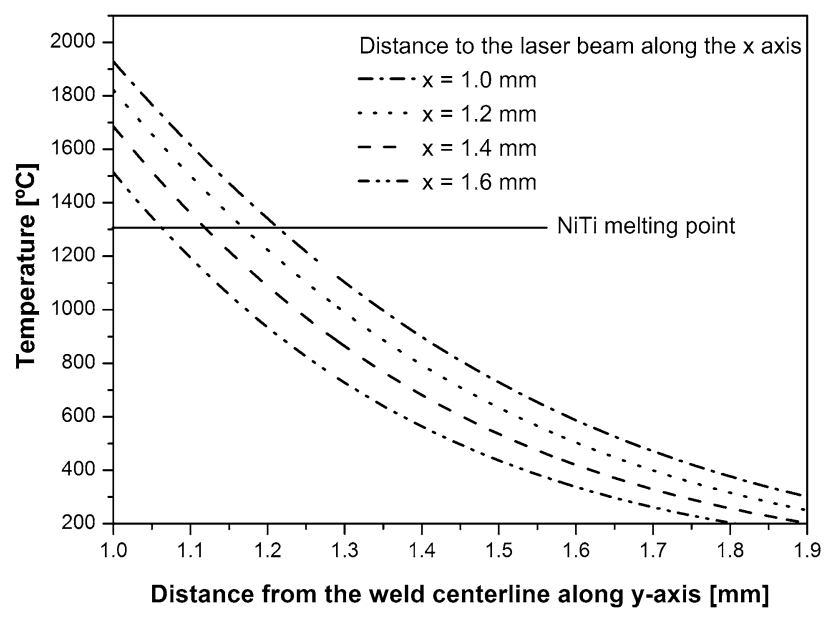

Fig. 6 Evolution of the surface temperature as a function of the distance to the weld beam along the y-axis, for sample A

from 15 to $30 \%$. For this reason, a post-weld heat treatment at a temperature of $450{ }^{\circ} \mathrm{C}$, during $60 \mathrm{~min}$, was performed. The objective of the post-weld heat treatment is to induce a more significant $\mathrm{Ni}_{4} \mathrm{Ti}_{3}$ precipitation so that more peaks of this precipitate can be observed. After a longer period in the temperature range for $\mathrm{Ni}_{4} \mathrm{Ti}_{3}$ precipitation occur, these precipitates are clearer in the X-ray diffraction patterns, as their intensity is higher due to a

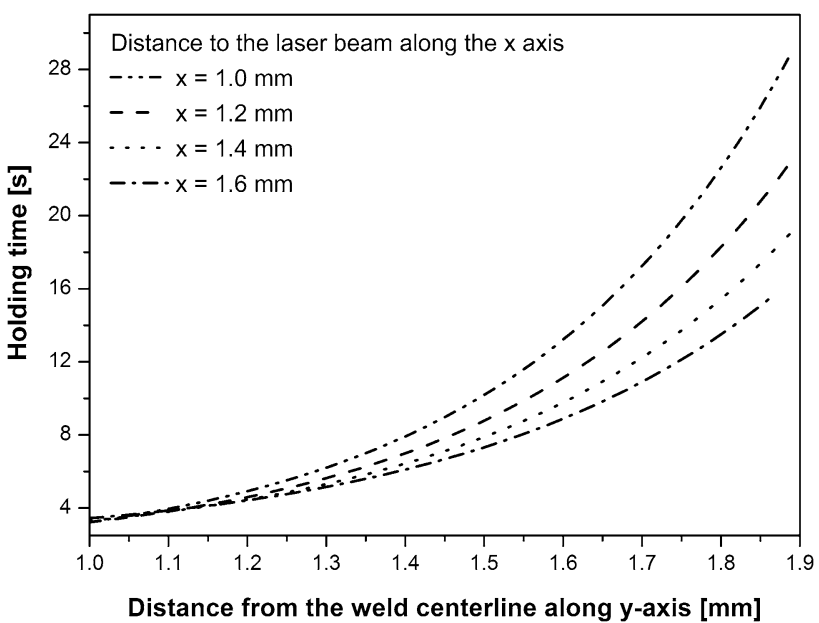

Fig. 7 Holding time, in the heat-affected zone, at an interval temperature of $350-500{ }^{\circ} \mathrm{C}$ where $\mathrm{Ni}_{4} \mathrm{Ti}_{3}$ precipitation may occur, for sample A

higher fraction in the analyzed region. Also, their appearance should be consistent with the positions identified in the heat-affected zone of the as-welded material, giving then a clear indication that these precipitates were well indexed.

Figure 8a, c depict the diffractograms of the heat-affected zone of the as-welded sample A, at RT and $150{ }^{\circ} \mathrm{C}$. Both martensite and austenite can be clearly observed at room temperature, but at $150{ }^{\circ} \mathrm{C}$ very narrow $\mathrm{Ni}_{4} \mathrm{Ti}_{3}$ peaks can be depicted, aside from the austenite peak. After the heat treatment, R-phase can be observed at room temperature, as well as austenite and martensite. The diffractograms of the sample at room temperature and at $150{ }^{\circ} \mathrm{C}$ (to avoid the presence of any martensite or R-phase peaks), after the post-welding heat treatment at $450{ }^{\circ} \mathrm{C}$ for $60 \mathrm{~min}$, are depicted in Fig. 8b, d, respectively. The broad peak in the neighborhood of the (110) austenite peak is still visible and three extra peaks corresponding to $\mathrm{Ni}_{4} \mathrm{Ti}_{3}$ are again observed. All these three peaks were indexed using the same 39-1113 JCPDF card corresponding to $\mathrm{Ni}_{4} \mathrm{Ti}_{3}$. As it can be depicted, the $\mathrm{Ni}_{4} \mathrm{Ti}_{3}$ peaks located on the left-hand side of the austenite peak have very low intensity after the heat treatment. So, the fact that they have very low intensity, for the X-ray diffraction analysis performed at $150{ }^{\circ} \mathrm{C}$, is understandable as the permanence time in the temperature range from 350 to $500{ }^{\circ} \mathrm{C}$ during cooling, after welding, is not sufficient for a massive/significant precipitation phenomena to occur.

Due to the occurrence of Ni-rich precipitates, in this case $\mathrm{Ni}_{4} \mathrm{Ti}_{3}$, there is a $\mathrm{Ni}$ depletion in the surrounding matrix [19]. This Ni depletion raises the transformation temperatures. This local composition variation on the matrix allows martensite to be formed at room temperature. As no changes in the diffraction patterns were observed, at 

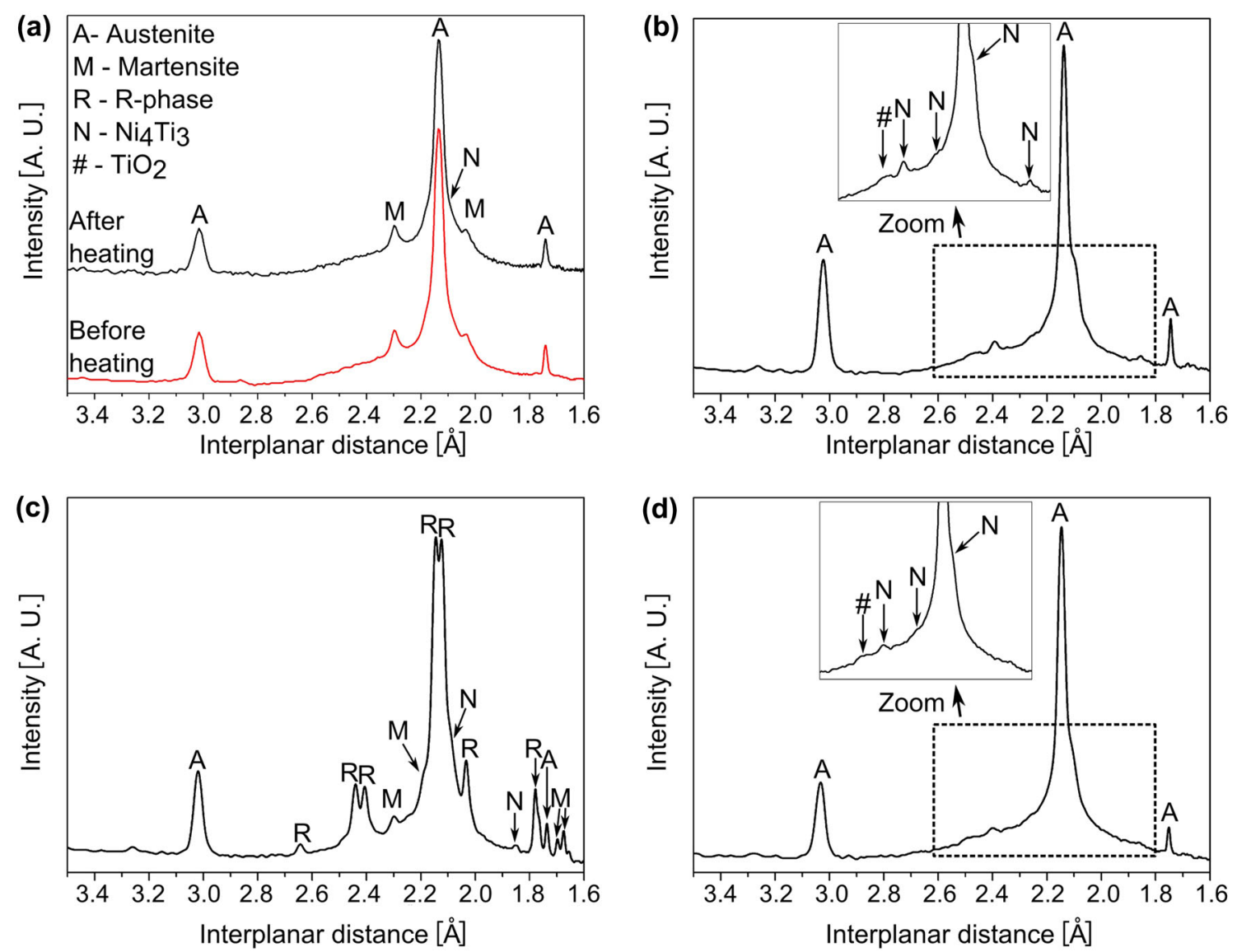

Fig. 8 Diffractograms of the heat-affected zone: a at room temperature (before and after heating up to $150{ }^{\circ} \mathrm{C}$ ), as-welded; $\mathbf{b}$ at $150{ }^{\circ} \mathrm{C}$, as-welded; $\mathbf{c}$ at room temperature, after post-weld heat treatment at

$450{ }^{\circ} \mathrm{C}$ for $60 \mathrm{~min}$; d at $150{ }^{\circ} \mathrm{C}$ after post-weld heat treatment at $450{ }^{\circ} \mathrm{C}$ for $60 \mathrm{~min}$

room temperature, before and after heating to $150{ }^{\circ} \mathrm{C}$ it can be concluded that the observed martensite is not due to thermal stresses from welding.

\section{Existence of Martensite in the Fusion Zone}

The fusion zone, as depicted in Figs. 3 and 4, also exhibits a martensitic phase. Hyungson et al. [20] state that, within the keyhole, the temperature may exceed the boiling point of the material, which causes an intense evaporation. At those temperatures, $\mathrm{Ni}$ and $\mathrm{Ti}$ volatilization can occur. Considering Fig. 9, the vapor pressure of $\mathrm{Ni}$ is about two times higher than that of Ti. For this reason, in case of evaporation, a $\mathrm{Ni}$ depletion occurs in the fusion zone. Figure 9 was made taking into consideration the equation $\log p=-\frac{A}{T}+B+C \log T$, for temperatures above the melting temperature $\left(\mathrm{T}_{\mathrm{m}}\right)$ of $\mathrm{Ni}$ and $\mathrm{Ti}$, where $\mathrm{p}$ is the vapor pressure (in $\mathrm{Pa}$ ), $\mathrm{T}$ is the temperature (in $\mathrm{K}$ ), and $\mathrm{A}$, $\mathrm{B}$, and $\mathrm{C}$ are constants (given in Table 2) [21].

Despite the presence of a shielding gas to prevent oxidation, evaporation of elements with high pressure vapor can occur during welding. Though these losses are very

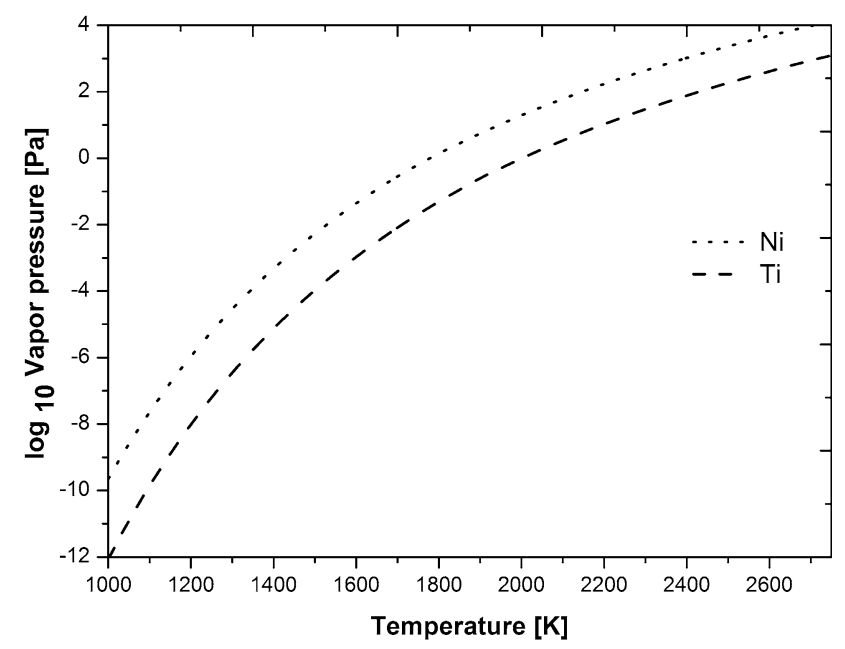

Fig. 9 Vapor pressure as a function of temperature for $\mathrm{Ni}$ and $\mathrm{Ti}$

small they can be sufficient to locally change the chemical composition in the fusion zone. Due to different vapor pressures of $\mathrm{Ti}$ and $\mathrm{Ni}$, a Ti enrichment is expected which 
Table 2 Constant parameters for calculating the vapor pressure of $\mathrm{Ni}$ and $\mathrm{Ti}[21]$

\begin{tabular}{lllll}
\hline Temperature range & Element & \multicolumn{4}{l}{ Constant values } \\
\cline { 3 - 5 } & & $\mathrm{A}$ & $\mathrm{B}$ & $\mathrm{C}$ \\
\hline Above $\mathrm{T}_{\mathrm{m}}$ & $\mathrm{Ni}$ & 22,400 & 16.95 & -2.01 \\
& $\mathrm{Ti}$ & 23,200 & 11.74 & -0.66 \\
\hline
\end{tabular}

is consistent with the existence of martensite at room temperature after welding as shown by our X-ray diffraction results.

\section{Conclusions}

The mechanisms responsible for the existence of martensite at room temperature after laser welding of austenitic NiTi were discussed using a detailed X-ray diffraction analysis.

Two different mechanisms were identified. Besides the preferential volatilization of the $\mathrm{Ni}$, which had been identified as responsible for the increase of the transformation temperatures in the fusion zone, it was also possible to identify a precipitation mechanism in the heat-affected zone as giving rise to the occurrence of martensite at room temperature. In both cases the compositional variation of the matrix greatly changes the transformation temperatures when compared to the base material.

Despite the existence of martensite in the heat-affected zone and in the fusion zone at room temperature after welding, austenite is still present. This change in the existing phases of laser-welded joints may be of great importance to understand the mechanical behavior of a welded component.

Acknowledgments JPO and FBF acknowledge funding by FEDER funds through the COMPETE 2020 Programme and National Funds through FCT-Portuguese Foundation for Science and Technology under the project UID/CTM/50025/2013. RMM acknowledges UID/ EMS/00667/2013. JPO acknowledges FCT/MCTES for funding PhD Grant SFRH/BD/85047/2012. The authors acknowledge DESY and HZG for beamtime and travel reimbursement under proposal I-20120563 EC FP7/2007-2013 Grant agreement no. 312284. The authors acknowledge the helpful discussion with Professor Yinong Liu from the University of Western Australia.
2. Falvo A, Furgiuele FM, Maletta C (2005) Laser welding of a NiTi alloy: mechanical and shape memory behavior. Mater Sci Eng, A 412:235-240

3. Sevilla P, Martorell F, Libenson C, Planell JA, Gil FJ (2008) Laser welding of NiTi orthodontic archwires for selective force application. J Mater Sci Mater Med 19:525-529

4. Gugel H, Schuermann A, Theisen W (2008) Laser welding of NiTi wires. Mater Sci Eng, A 481-482:668-671

5. Chen Y, Ke L, Liu Y, Xu S (2010) Laser butt welding of TiNi shape memory alloy sheet. Adv Mater Res 97-101:3936-3939

6. Falvo A, Furgiuele FM, Maletta C (2006) Functional behaviour of a NiTi-welded joint: two-way shape memory effect. Mater Sci Eng, A 481-482:647-650

7. Khan M, Zhou Y (2010) Effects of local phase conversion on the tensile loading of pulsed Nd:YAG laser processed Nitinol. Mater Sci Eng, A 527:6235-6238

8. Oliveira JP, Braz Fernandes FM, Schell N, Miranda RM (2015) Shape memory effect of laser welded NiTi plates. Funct Mater Lett 8(6), 1550069

9. Tuissi A, Besseghini S, Ranucci T, Squatrito F, Pozzi M (1999) Effect of Nd-YAG laser welding on the functional properties of the Ni-49.6at.\%Ti. Mater Sci Eng, A 273-275:813-817

10. Hsu YT, Wang YR, Wu SK, Chen C (2001) Effect of $\mathrm{CO}_{2}$ laser welding on the shape-memory and corrosion characteristics of TiNi alloys. Metall Mater Trans A 32A:569-576

11. Khan MI, Pequegnat A, Zhou YN (2013) Multiple memory shape memory alloys. Adv Eng Mater 15:386-393

12. Song YG, Li WS, Li L, Zheng YF (2008) The influence of laser welding parameters on the microstructure and mechanical property of the as-jointed NiTi alloy wires. Mater Lett 62:2325-2328

13. Kou S (2003) Welding metallurgy. Wiley Interscience

14. Ke C, Cao S, Ma X, Zhang X (2012) Modeling of Ni4Ti3 precipitation during stress-free and stress-assisted aging of bi-crystalline NiTi shape memory alloys. Trans Nonferrous Metals Soc China 22:2578-2585

15. Otsuka K, Ren X (1999) Recent developments in the research of shape memory alloys. Intermetallics 7:511-528

16. Nishida M, Wayman CM, Honma T (1986) Precipitation processes in near-equiatomic TiNi shape memory alloys. Metall Trans A 17A:1505-1515

17. Pelton AR, DiCello J, Miyazaki S (2000) Optimisation of processing and properties of medical grade Nitinol wire. Minim Invasive Ther Allied Technol 9:107-118

18. Steen W, Mazumder J (2010) Laser material processing. Springer

19. Neves F, Cunha A, Martins I, Correia JB, Oliveira M, Gaffet E (2008) Ni4Ti3 precipitation during ageing of MARES NiTi shape memory alloys studied by FEG-SEM. Microsc Microanal 14:13-16

20. Hyungson K, Mohanty P, Mazumder J (2002) Modeling of laser keyhole welding: part II. simulation of keyhole evolution, velocity, temperature profile, and experimental verification. Metall Mater Trans A 33A:1831-1842

21. Gale WF, Totemeir TC (2004) Smithells metals reference book. Elsevier

\section{References}

1. Otsuka K, Ren X (2005) Physical metallurgy of Ti-Ni shape memory alloys. Prog Mater Sci 50:511-678 